\title{
Impact of repeated administration of Cannabis sativa on some biochemical parameters in albino rats
}

\author{
${ }^{1}$ Okwari, O. O., ${ }^{2}$ Emerole C .G, ${ }^{3}$ Dasofunjo K, ${ }^{4}$ Alagwu E.A,,${ }^{5}$ Olatunji T.L and \\ ${ }^{6}$ Osim, E. E \\ ${ }^{I}$ Department of Physiology, Cross River University of Technology, Okuku, Nigeria \\ ${ }^{2}$ Optometry Unit Eye Clinic, Federal Medical Centre, Owerri, Nigeria \\ ${ }^{3}$ Department of Medical Biochemistry, Cross River University of Technology, Okuku, Nigeria \\ ${ }^{4}$ Department of Physiology, College of Medicine and Health Sciences .Imo State University, Owerri, Nigeria \\ ${ }^{5}$ Department of Plant Biology, University of Ilorin, Ilorin, Nigeria \\ ${ }^{6}$ Department of Human Physiology, University of Calabar, Calabar ,Nigeria
}

\begin{abstract}
Cannabis sativa is an illicit drug with proven anti-inflammatory, analgesic, antipyretic and anti diarrhea activities. This present study is aimed at ascertaining the impact of Cannabis sativa on some biochemical indices of albino rats. Twenty (20) male wistar albino rats ranging from $180-200 \mathrm{~g}$ were acclimated to laboratory conditions for 7 days, following which they were randomly assigned into 4 groups $i$, ii, iii and iv of five animals each based on average body weight. Groups (ii-iv) were administered $0.5 \mathrm{ml}$ aqueous extract of Cannabis sativa via oral route corresponding to 1,2 and $3 \mathrm{mg} / \mathrm{Kg} /$ body weight, while group $i$ (control) received $0.5 \mathrm{ml}$ of distilled water orally. Rats in all groups were sacrificed 24hours after the experimental periods of 30daysoforaladministration of the extract. The extract significantly $(p<0.05)$ increased serum Albumin, Globuli $n$, Total protein, Conjugated bilirubin while Total bilirubin, unconjugated bilirubin concentration showed a significant $(p<0.05)$ increase only in group ii and iv when compared with the control. Likewise group ii and iii showed a significant $(p<0.05)$ reduction in total cholesterol. The serum AST and ALT showed a significant $(p<0.05)$ increase when compared with the control. The alterations by the results are manifestation of mild hepatorenal toxicity and anti-hypercholesterolemic effect.

Keywords: Analgesic,anti-hypercholesterolemic,anti-inflamatory, Cannabis sativa hepatorenal,
\end{abstract}

\section{Introduction}

Cannabis sativa is a dioecious (having male and female flowers in separate plants), green, leafy plant with characteristic opposite, usually seven-fingered, lance-shaped leaves; on dry, sandy, slightly alkaline soil it can grow to more than seven meters in height. Glandular hairs develop, usually on the female flower, which secrete a resin. The female plants are more important than the male plants for commercial purposes: their fibres are thicker, they form the nutritious seeds, and they contain the psychoactive principle tetra hydro cannabi-nol (THC) [1] .

Over the years, Cannabis remains the most widely used illicit drug worldwide due to its affordability and availability [2]. Besides, cannabis is a major controversial drug as there are numerous conflicting and controversial reports concerning its psychological and physiological effects [3]. Many reports have linked cannabis smoking to the development of psychosis [4]. Certain studies have also suggested that cannabis smoking is only a form of self-medication in people with psychotic symptoms rather than a causative factor in development of psychosis [5]. Recently, there seems to be an increase in the number of reports lending support to cannabis psychosis. Further, a review of the evidence surrounding the acute impact on memory concluded that cannabinoids impair all aspects of short-term memory, especially short-term episodic and working memory [6]. Apart from the psychological effects, various reports have shown that cannabis smoking has significant physical effects on the body $[7,8]$. Cannabis has been found to increase heart rate by $20-50 \%$. This is the most immediate effect and occurs within a few minutes after cannabis intake. After, cannabis usage, a sudden change of posture from lying down to standing up may produce orthostatic hypotension, a feeling of 'light-headedness' and faintness that is often the earliest indication of intoxication in naive users [9]. Other physical effects of cannabis include reddening of the eyes due to congestion of the conjunctiva blood vessels, lowering of the body temperature, dry mouth, reduced intraocular pressure and relaxation of the muscles [10]. Cannabinoids have also been shown to affect the immune system [11].Clinical studies and survey data have found that cannabis increases appetite [12]. The $\Delta^{9}$-tetrahydrocannabinol (THC) which is the main constituent of cannabis has been shown to have effect on both the action and the release of insulin [13]. This may explain why cannabis has been employed to self-medicate in diabetes. Cannabis has also been reported to have medicinal use in treating depression [14]. Cannabis sativa have also been reported to be used for treatment of specific human ailments such as allergies, burns, cuts and wounds, inflammation, leprosy, leucoderma, scabies, smallpox and sexually 
transmitted diseases [15]. The different preparation of Cannabis sativa has been used in Asian traditional medicine for treatment of variety of diseases including: inflammation, nausea, headache, hematochesia, diarrhea, and alopecia $[16,17,18]$ have demonstrated a potent anti-inflammatory, analgesic, antipyretic and antidiarrhea activities

In the developing countries, like Nigeria, data available is scarce as well as reliable information of actual and potential health consequences, which could give input into health analysis of national developmental strategies. Actual evidence of chronic health effect of cannabis sativa can be provided in the laboratory using experimental animals models in which well controlled doses are administered over a period of time. Therefore this research is focused on the impact of cannabis sativa on some biochemical parameters in albino rats.

\section{SAMPLES}

\section{Materials And Methods}

The plant materials was collected from a local farm in Akpet and authenticated at the Botanical unit of the Biological Science Department, University of Calabar, Nigeria. The crude extract was prepared according to the method described by [19]. The leaves were oven dried at $45^{\circ} \mathrm{C}$ and hundred grams of the dried fruit materials was pulverized and soaked for 72 hours in $800 \mathrm{mls}$ of distilled water. It was then filtered with Whatman No 1 filter paper and the residue discarded. The filtrate was subsequently evaporated to dryness in an aerated oven at $45^{\circ} \mathrm{C}$. The resulting slurry was stored in closed cab bottles until used.

\section{Animals and treatment protocols:}

Twenty (20) wistar albino rats weighing $\mathbf{1 8 0 - 2 0 0 g}$ were used for this work. The animals were obtained from the animal holding unit of the Department of Human Physiology, University of Calabar, Calabar, Cross River State. The animals were housed in plastic cages and were allowed acclimatization period of Seven (7) days in a well-ventilated room with a temperature and pressure of $29 \pm 2{ }^{\circ} \mathrm{C}$ and $70 \%$ respectively. The wistar albino rats were maintained with rat chow (vital feeds Ltd) and water ad libitum. The animals were exposed to 12 hours light -dark cycle and handled according to standard protocols. At the end of acclimatization period, they were divided into four groups i, ii , iii and iv of five (5) rats each. Group i served as control while ii - iv were the test group .The control group was treated with $0.5 \mathrm{mls}$ of normal saline while B and C were treated with 0.5 $\mathrm{mls}$ corresponding to 1,2 , and $3 \mathrm{mg} / \mathrm{kg}$ body weight of the $\operatorname{drug}$ (Cannabis sativa) respectively and were administered orally for Thirty days (30) days. The wistar albino rats were sacrificed 24 hours after the last administration in accordance with the guide lines of the European Convention for the protection of vertebrate animals and other scientific purposes-ETS-123[20].

\section{Preparation of Serum.}

The animals were anaesthetized in a jar containing cotton wool soaked in diethyl-ether and chloroform in ratio1:1. When the animal became unconscious, they were brought out quickly of the jar, the abdominal region was opened along the linear Alba and diaphragm cut with scalpel blade to expose the organs and blood was collected into a sterile sample container by cardiac puncture. Blood was collected into a clean, dry centrifuge tube and allowed to clot for $30 \mathrm{~min}$ before centrifuging at 300rpm x 10min using Uniscope Laboratory Centrifuge. The serum was thereafter aspirated into clean, dry, sample bottles using Pasteur pipette and was kept or stored in sample bottles and used within 12hours of preparation as described by [21]. Later it was transferred into specimen bottles before being used for biochemical analysis.

\section{Statistical Analysis}

Statistically analysed data used was presented as mean \pm SD of five (5) determinations. Statement analysis was carved out using one way analysis of variance (ANOVA). Differences were statistically significant at $\mathrm{P}<0.05$ [22].

\section{Results}

The results depict the effect of Cannabis sativa on some biochemical parameters indices of Wistar albino rats. Fig 1-2 showed the effect of Cannabis sativa on serum AST and ALT of Wistar albino rats, though, group ii showed no significant difference when compared with the control but both group iii and iv showed a significant $(\mathrm{P}<0.05)$ increase when compared with the control. More so, the total bilirubin in group ii and group iv showed a significant $(\mathrm{P}<0.05)$ increase when compared with the control. While group iii was significantly $(\mathrm{P}<0.05)$ reduced when compared with the control (Fig3).The conjugate bilirubin showed a significant $(\mathrm{P}<0.05)$ decrease in group ii when compared with the control while group iii and iv showed a significant $(\mathrm{P}<0.05)$ increase when compared with the control (Fig 4). The effect of Cannabis sativa on serum unconjugated bilirubin on Wistar albino rats showed a significant $(\mathrm{P}<0.05)$ increase in group ii and iii but significant $(\mathrm{P}<0.05)$ decrease 
when compared with control (Fig 5). The drug also reveals a significant $(\mathrm{P}<0.05)$ increase when compared with the control in animals in group ii but a significant $(\mathrm{P}<0.05)$ decrease following the administration of the drug in both group iii and iv respectively(Fig vi).On the other hand, Total protein showed a significant( increase in all the experimental groups as seen in (Fig 7).Similar patterns was also shown in albumin and globulin(Fig 8-9).Fig 10 showed a significant decrease in albumin /globulin ratio in all the experimental groups.

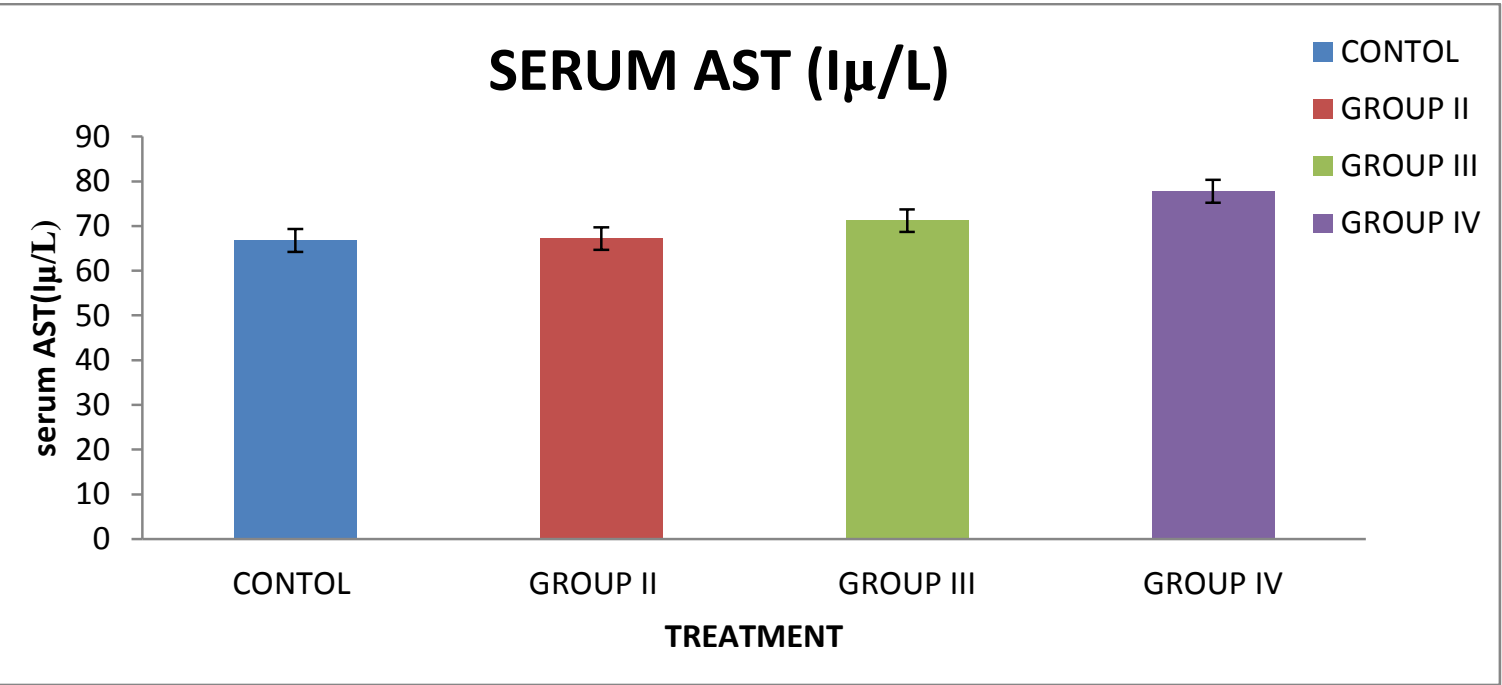

Fig 1:Effect of Canabissativa on Serum AST of Wistar Albino Rats

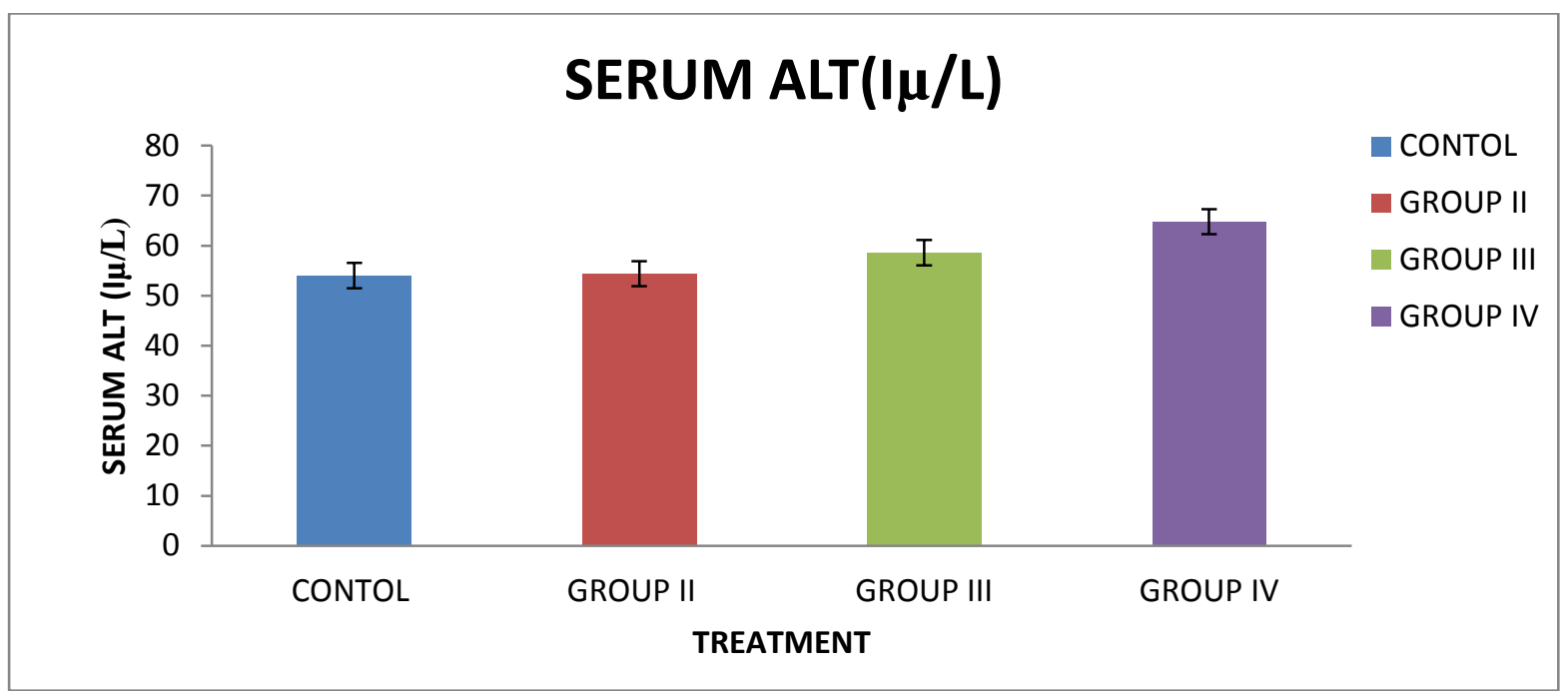

Fig 2:Effect of Canabissativa on Serum ALT of Wistar Albino Rats 


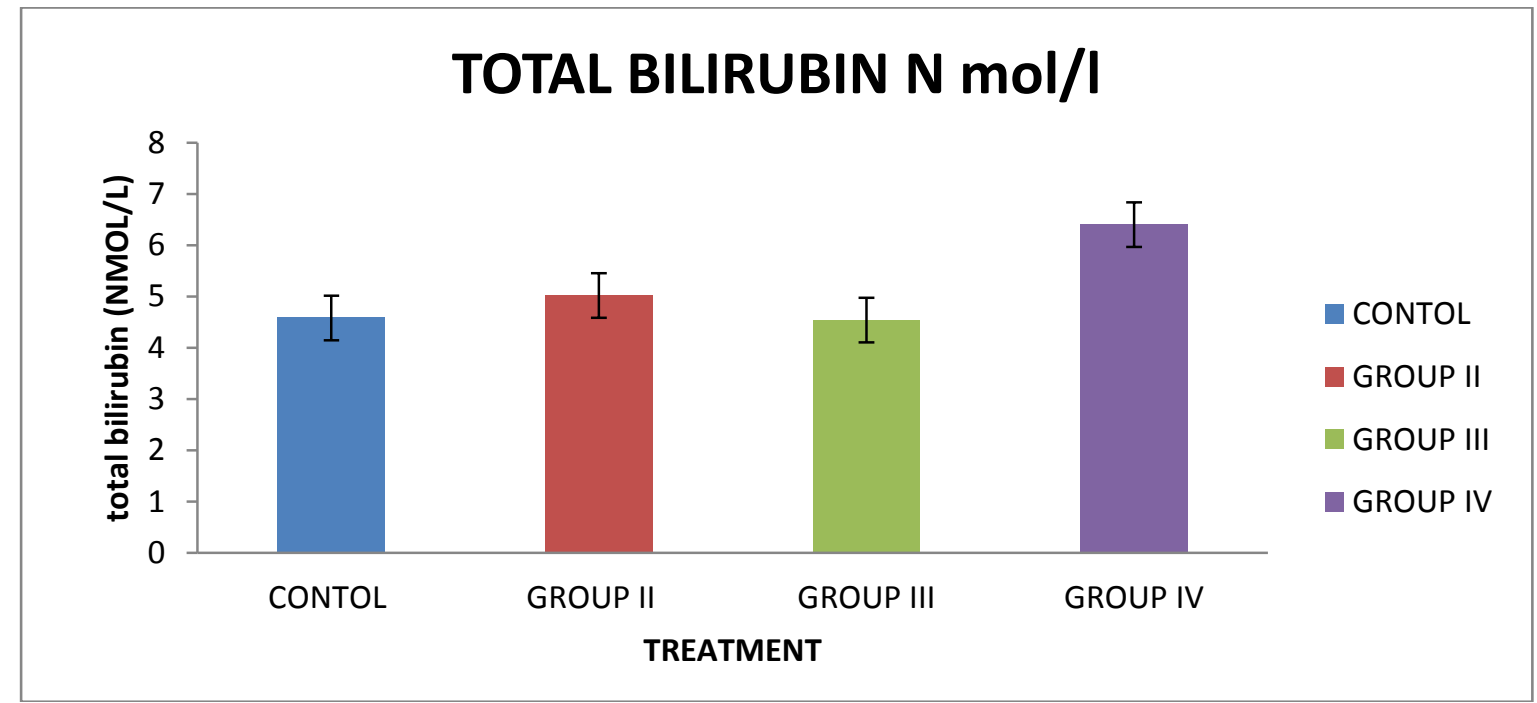

Fig 3:Effect of Canabissativa on Serum Total Bilirubin of Wistar Albino Rats

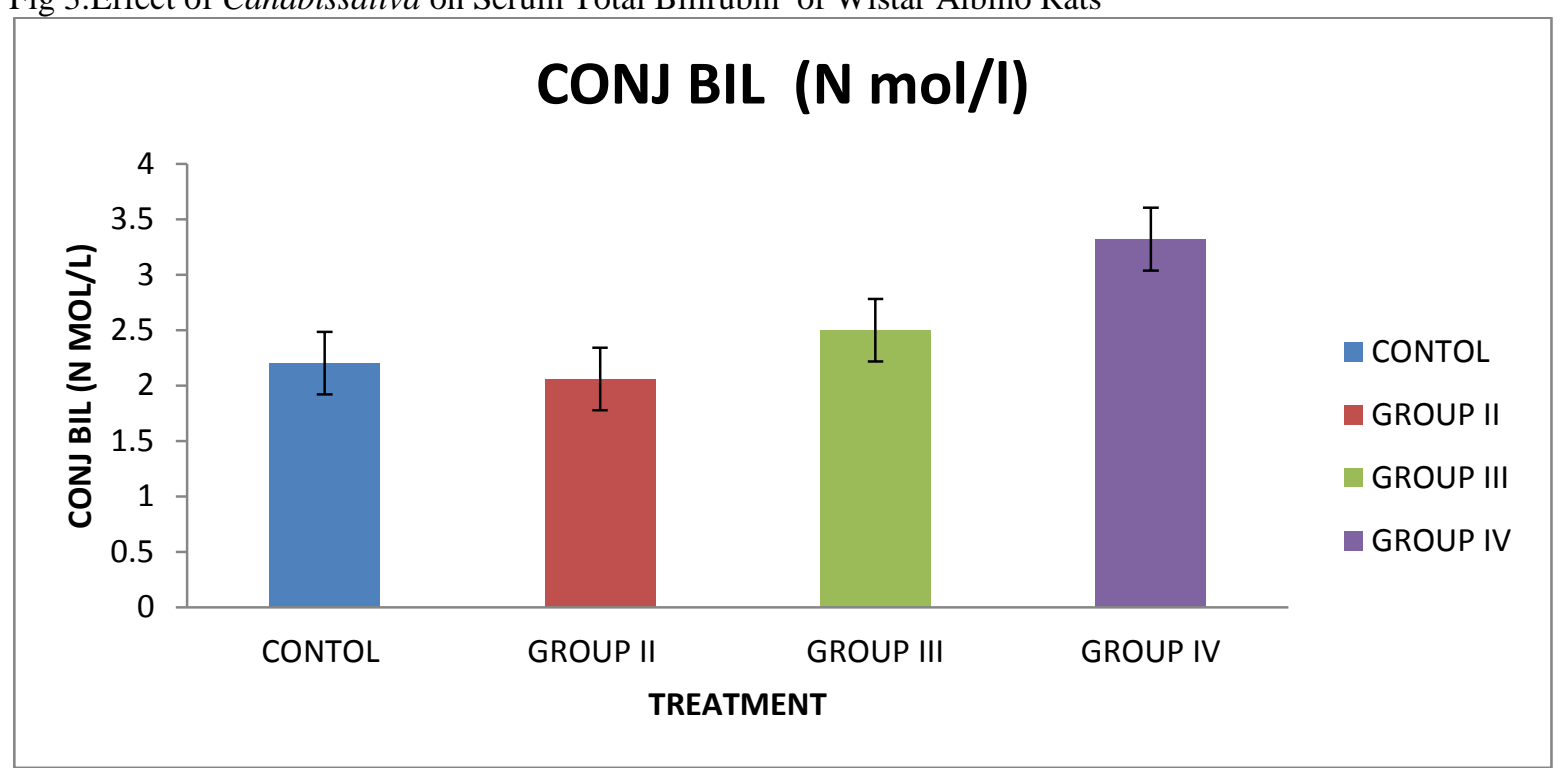

Fig 4:Effect of Canabissativa on Serum Conjugated Bilirubin of Wistar Albino Rats

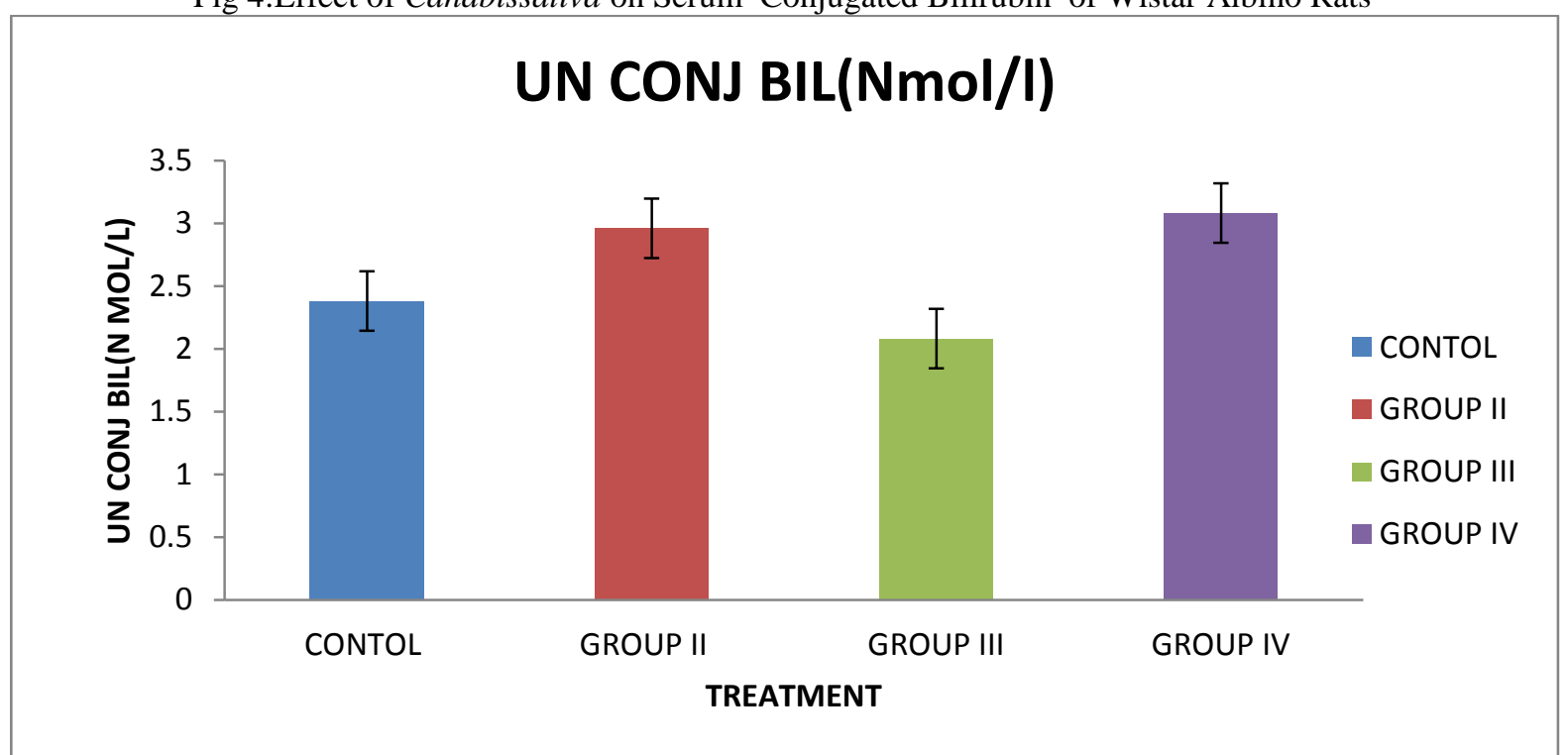

Fig 5:Effect of Canabis sativa on Serum Unconjugated Bilirubin on Wistar Albino Rats 


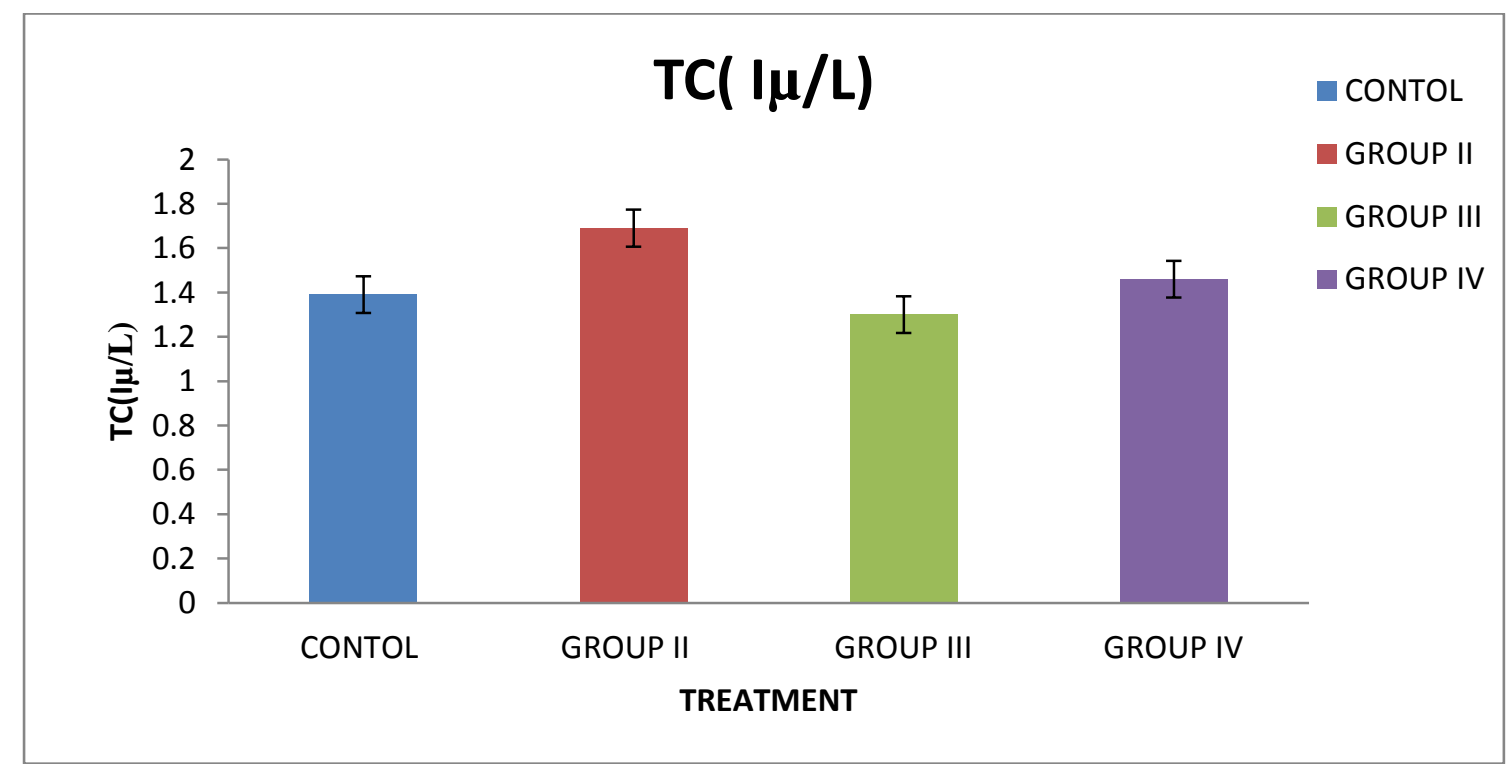

Fig 6:Effect of Canabis sativa on Serum Total Cholesterol of Wistar Albino Rats

\section{$\operatorname{TP}(I \mu / L)$}

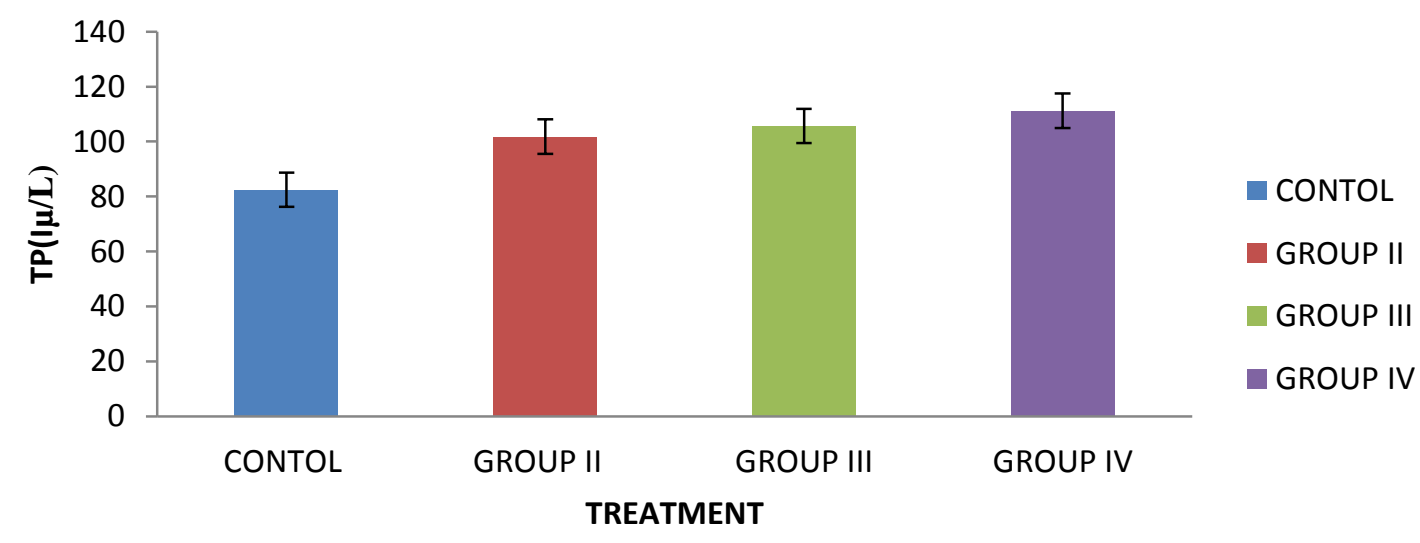

Fig 7:Effect of Canabis sativa on Serum Total Protein of Wistar Albino Rats

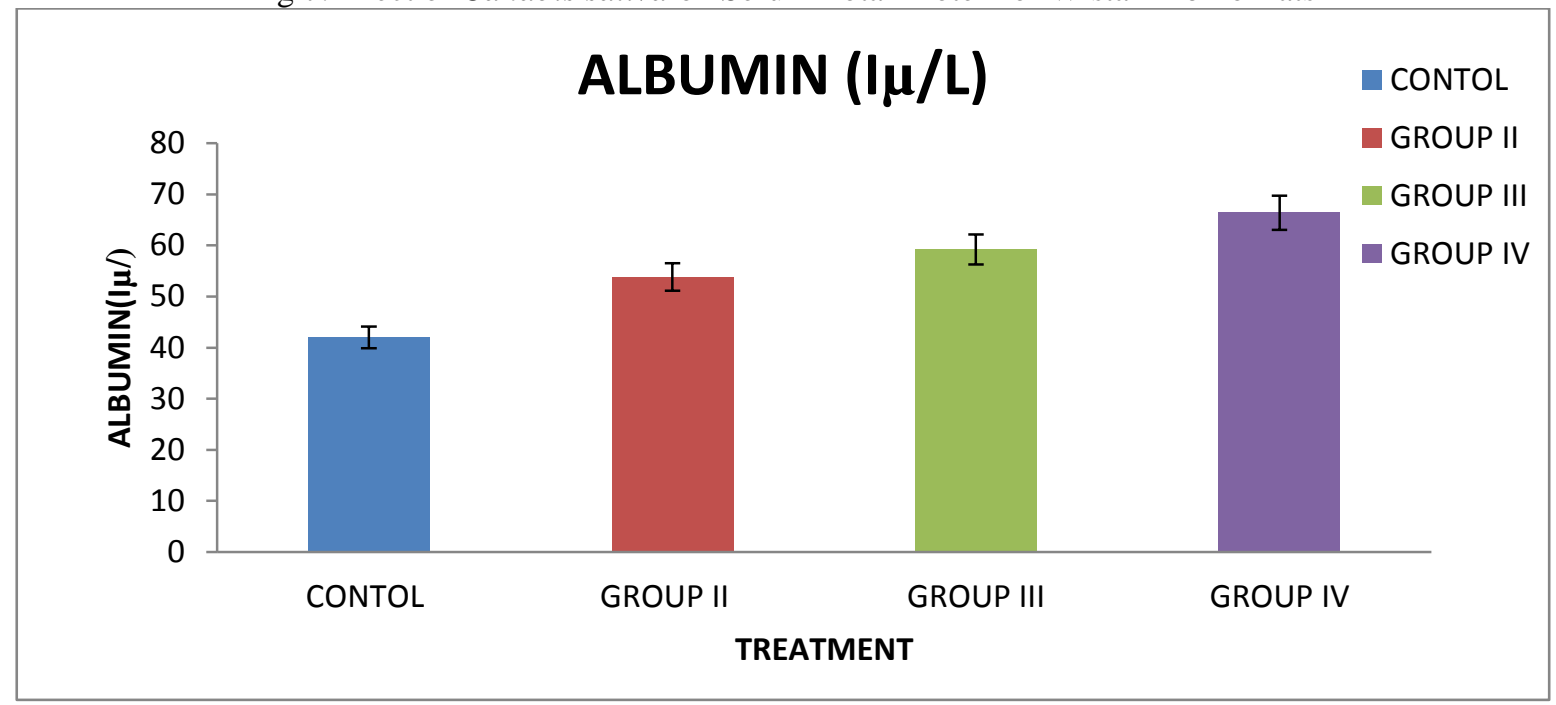

Fig 8:Effect of Canabis sativa on Serum Albumin of Wistar Albino Rats 


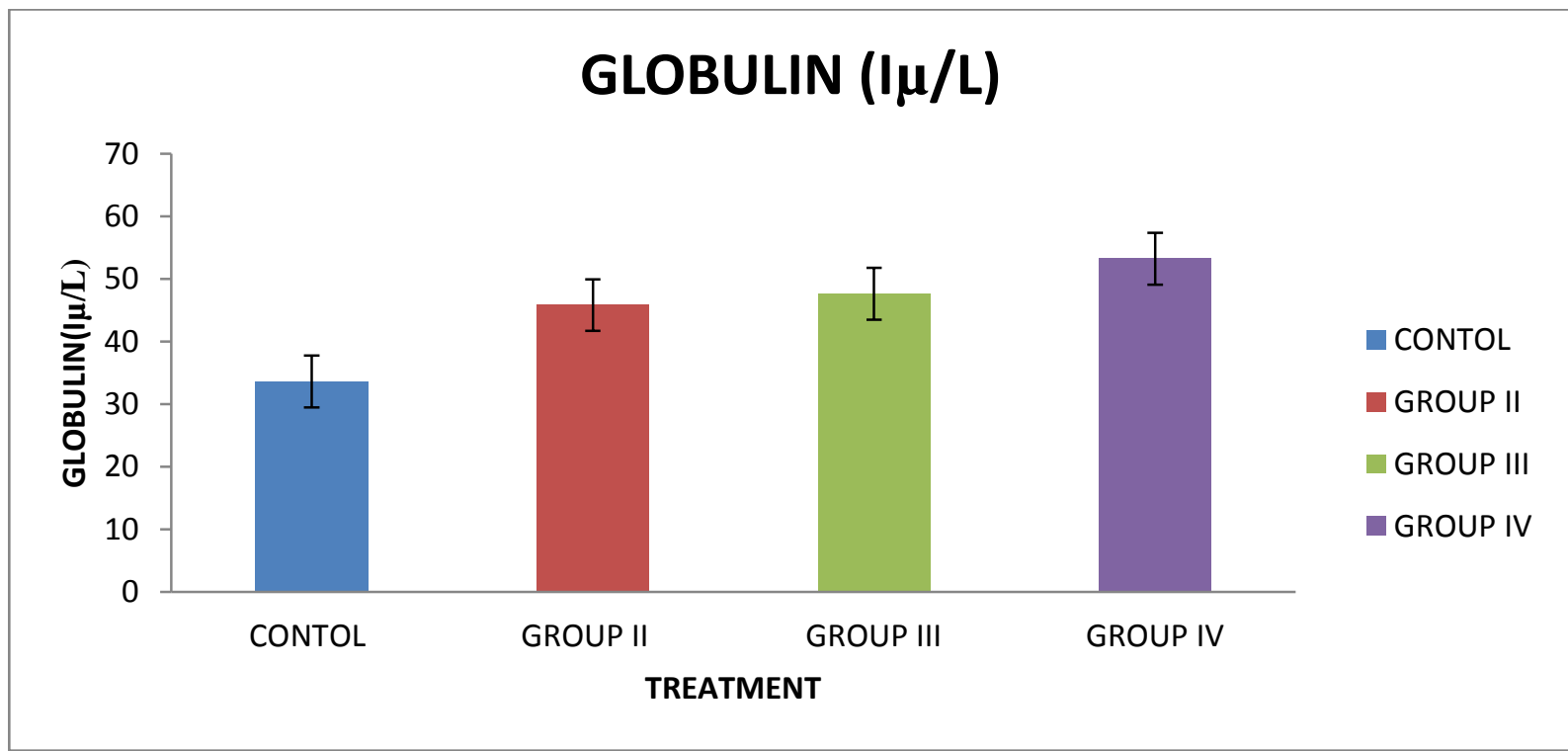

Fig 9:Effect of Canabis sativa on Serum Globulin of Wistar Albino Rats

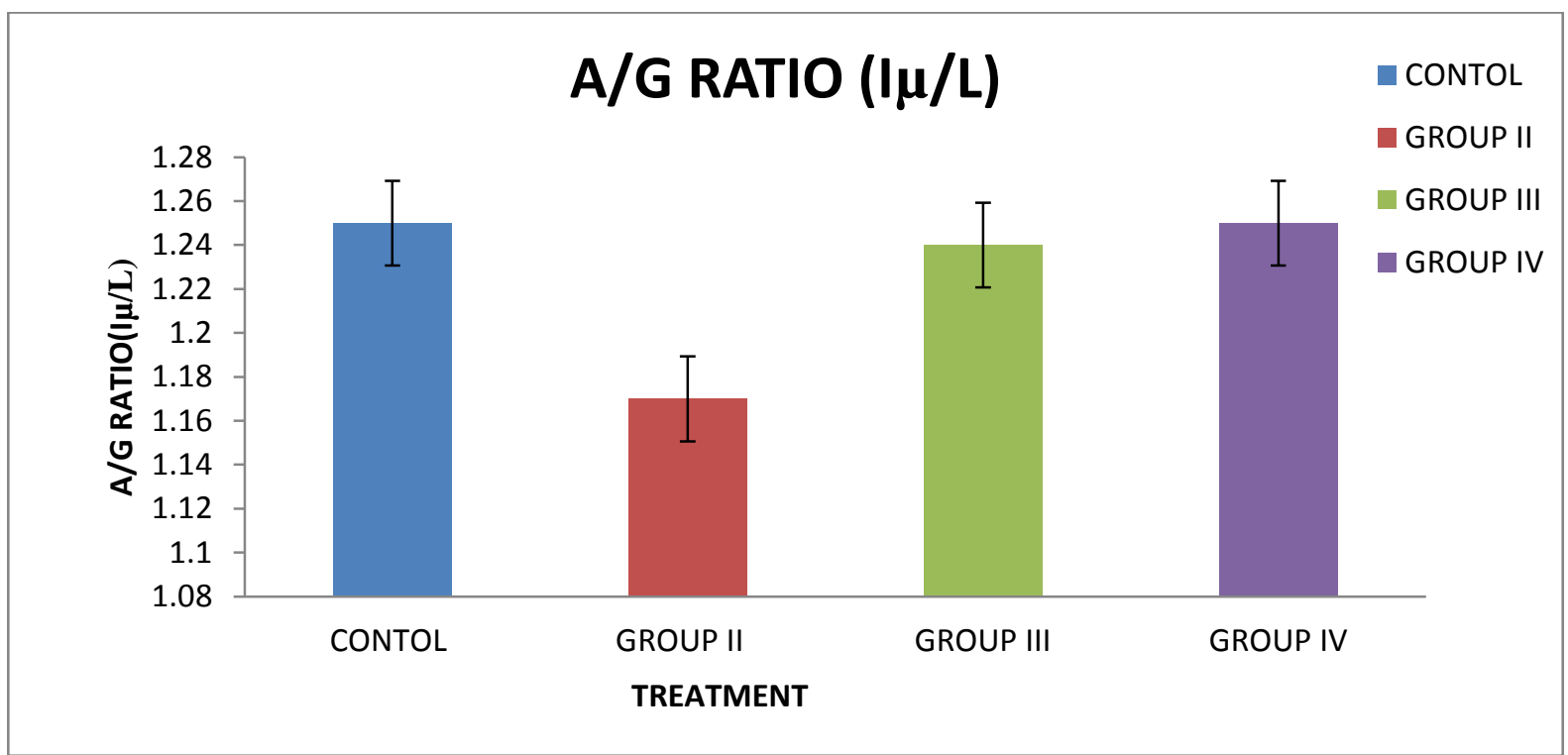

Fig 10:Effect of Canabis sativa on Serum Albumin/Globulin Ratio of Wistar Albino Rats

\section{Discussion}

The Liver has an incontrovertible influence on several functions of many organs in the body. It is prone to xenobiotic induced injury due to its central role in xenobiotic metabolism and its portal location within the system [23].The liver plays important role in metabolism, detoxification and biotransformation .Therefore, an alteration in the biomarkers of the liver function indices might be used to monitor the level of injury or damage by the plant extract before biopsy [24]

The observed significant $(\mathrm{p}<0.05)$ increase the Albumin, Globulin, Total protein and Total bilirubin concentration implied that the extract produced an increase in protein synthesis and (or) mobilization. Moreso the observed increase in Globulin level may indicate the efficiency of the plant extract to produce antibody [25] or due to the presence of bioactive constituent like flavonoids and alkaloids.

Albumin is the protein with the highest concentration in the plasma. It transports many molecules in the blood. It prevents the fluid in the blood from leaking out the tissue [26]. Albumin is a constituent of the total protein produced in the liver. Albumin levels are decreased in chronic liver disease such as cirrhosis or nephrotic syndrome. Therefore, the observed increase in serum albumin is an indication that the Cannabis sativa may promote good functioning of the liver or might possess a hepatoprotective role and may help calcium in the blood stream to regulate the movement of water blood stream into body tissue [27]. This is also supported by the result displayed by the albumin /globulin ratio and significant increase seen in total protein concentration. However, the significant increase in the serum level of both total bilirubins, unconjugated and conjugated 
bilirubin is an indication that the drug might induce injury to the hepatic tissue or caused conjugated hepatobilliary injury on the wistar albino rats [28].

Serum Alanine Amino Transferase (ALT) is known to increase when there is liver disease and it has been used as a tool for measuring hepatic necrosis $[29,26]$. Hence, the observed increase in serum ALT suggests that extract may not be safe to the hepatic tissue at 1,2 and $3 \mathrm{mg} / \mathrm{kg}$ body weight. Aspartate Amino Transaminase (AST) is predominantly localized within the cells of the gills, kidney, muscle and liver parenchyma cells. The observed increase in serum AST might connote acute liver damage or liver cytolysis.ALP is a marker enzyme for the plasma membrane and endoplasmic reticulum [30] or cell lining of the biliary ducts of the liver, placental tissue and bone. The significant decrease in total cholesterol in group iii and iv following the administration of the drug suggest that the drug exhibits an antilipidaemic or antihypercholesterolemic or cholesterol lowering effect.

\section{Conclusion}

It may therefore be too hasty to conclude that the drug was responsible for liver or hepatorenal toxicity as observed in the serum enzymes. More studies are highly imperative so as to be able to understand fully the various effects and mechanisms of cannabis on smokers. Though, it appears that the drug can enhanced protein synthesis, mobilization and antihypercholesterolemic or cholesterol lowering effect. Further studies can also reveal other possible pharmacologically active substance(s) that may have a good medicinal value, present in the drug.

\section{References}

[1]. I.B Adams and B.R Martin, Cannabis: Pharmacology and toxicology in animals and humans, Addiction 91(11), 1996,1585-1614; Geschwinde,

[2]. A. Bauman and P. Phongsavan. Epidemiology of substance use in adolescence: prevalence, trends and policy implications. Drug Alcohol Depend.55: 1999,187-207.

[3]. T.H.Richardson .Cannabis use and mental health:A review of recent epidemiologicalresearch.Int.J.Pharmacol .,6: 2010,796-807

[4]. W.Hall, and L.Degenhardt,Cannabis use and the risk of developing psychotic disorder.World Psychiatry,7: 2008,68-71.

[5]. S.H., Abdelrahman,I.M. Mousa, S.M.E. Khojali and A.A. Ismail Trypanocidal effect of Cannabissativa on experimental camel trypansomosis.Res.J.Med.Plant,6: 2012,281-285.

[6]. M.Ranganathan, and D.C.D'souza. The acute effects of cannabinoids on memory in humans:Areview.Psycho pharmacology188:2006,425 444.

[7]. R.V.Fant, S.J. Heishman, E.B.Bunker and W.B. Pickworth. Acute andresidual effects of marijuana in humans. Pharmacol.Biochem.Behav. 1998

[8]. M.Hashibe, H. Morgenstern, Y. Cui, D.P. Tashkin4 and Z.F. Zhang, Marijuana use and the risk of lung and upper aerodigestive tract cancers: Results of a population-based case-control study.Cancer Epidemiol. Biomarkers Prev.,15: 2006,1829-1834.

[9]. R.T Jones, Cardiovascular system effects of marijuana. J.Clin. Pharmacol.,42:2002,58S-63S.

[10]. F.Grotenhermen.The toxicology of cannabis and cannabis prohibition. Chem.Biodivers.,4: 2007,1744- 1769

[11]. H.Friedman,C. Newton and T.W. Klein.Microbial infections, immunomodulation, and drugs of abuse. Clin.Microbiol. Rev.16: 2003,209219

[12]. M. Tehranipour,and S. Ebrahimpour. Evaluating the effect of aquatic extract of Cannabis sativa seed on spatial memory consolidation in rats. J.Biol. Sciences, 9: 2009,884-888

[13]. M.Frisher, S. White, G. Varbiro, C. Voisey and D. Perumal. The role of cannabis and cannabinoids in diabetes.Br.J.Diabetes Vasc.Dis.,10:2010,267-273.

[14]. C.Henquet,and R.Kuepper. Does cannabidiol protect against the negative effects of theTHC?.Br.J.Psychiat ry,197:2010,259-260.

[15]. B .Dilaraand S.C Nath,Ethnobotanical review of medicinal plants used for skin diseases and related problems in Northeastern India. Journal of Herbal Spices and Medicinal Plants.7(3): 2000,55- 93.

[16]. M.J. McPartlandRandom queries concerning the evolution of Cannabis and coevolution with the cannabinoid receptor. In: Guy. G., 2004.

[17]. S. Dewan, S. Kumar, and V.1. Kumar, Anti-pyretic effect of Latex of Caltropisprocera. Ind. J. Pharmacol., 32: 2000,522

[18]. V.1. Kumar,and N. Basu,Anti-inflammatory activity of Latex of Caltropisprocera. J. Ethnopharmacol., 44: 1994,123- 125.

[19]. ObiefunaP.C.M,OwolabiO.A,AdegunloyB.J,Obiefuna I.P and Sofola O.A(1998).Retal Extract of Hisbiscussabdariffa produce relaxation of isolated Rat Aorta .Int.J.Pharmacology 32: 69-74.

[20]. European Treaty Series.European convention for experimental and other scientificpurposes.European Treaty Series, Strasbourg, ETS$2005,123$.

[21]. S.O.Malomo ,Toxicological implication of ceftriaxone administration in rats.Nig. J-Biochem and Mol. Boil. 15(1) 2000,,33-38

[22]. B.K.Mahajan.Significanceofdifferences in means.Methodsin biostatistics for medical and research workers, $6^{\text {th }}$ Ed.NewDelli JAYPEE Brothers medical publishers 1997, 130-155.

[23]. A.L. Jones. Anatomy of the normal liver disease, $3^{\text {rd }}$ Ed. Philadelphia.WB Saunders: 1996,3-32.

[24]. K.Dasofunjo,O.F.C.Nwodo,O.E.Yakubu,.R.Ejoba.R.U.Ukpanukpong,S.S.Ipav,M.N.Ugwu,A.I.Okafor,andS.L. Girgi).Hepatoprotective Effect of Pilliostigmathonningii Leaves on Male Wistar Albino Rats.Asian Journal of Plant Science and Research 3(4): 2013,13-17

[25]. A. Puri, R. Sesenu, K.C. Saxena,Immunostimulant Agent FromAndrographis. 1993

[26]. G.E. Duncan, S.S. Moy J.A., Lieberman, B.H. Koller, Typical and Antipsychotic drug effect on locomotor Hyperactivity and deficits in Sensorimortorgating in genetic model of MNDA receptorhypofunction. Pharmacol.Biochem.Behav.10(85): 2006,481-491.

[27]. K.Dasofunjo, O. FCNwodo., J. T. John, R. UUkpanukpong., and Ayo V. I. (2013). Phytochemical screening and effect ofethanolic leaf extract of Piliostigmathonningii on lipid profile of male albino rats. Journal of Natural Production and Plant Resources.3(2): 5-9

[28]. O.O. Okwari, A.O.Obembe and .KDasofunjo .Alterations of Evan He al thy Bitters on Some Biochemical Parameters of Wistar Albino Rats. Australian Journal of Basic and Applied Sciences, 7(9): 2013,58-62

[29]. B.M. Bush, Interpretation of laboratory results for small Animal clinicians. Oxford, Blackwell Scientific Publications. 1991,25-34.

[30]. M.Shahjahan, K.E.Sabitha, J.Malbika, C.S.Shyamala-Devis, Effect ofSolanumTrilobatum against carbon tetrachloride induced hepatic damage in albino rats. Indian. J. Med. Res. 120: 2004,194-198. 